\title{
UCLA
}

Mester

Title

Charla con José Saramago

Permalink

https://escholarship.org/uc/item/3nq1z921

Journal

Mester, 30(1)

Author

González, Oscar

Publication Date

2001

DOI

10.5070/M3301014551

Copyright Information

Copyright 2001 by the author(s). All rights reserved unless otherwise indicated. Contact the author(s) for any necessary permissions. Learn more at https://escholarship.org/terms

Peer reviewed 


\section{Charla con José Saramago}

"In one sense it could even be said that, letter-by-letter, word-by-word, page-by-page, book after book, I have been successively implanting in the man I was the characters I created. I believe that without them I wouldn't be the person I am today; without them maybe my life wouldn't have succeeded in becoming more than an inexact sketch, a promise that like so many others remained only a promise, the existence of someone who maybe might have been but in the end could not manage to be."

José Saramago, Nobel Acceptance Speech, 1998

El pasado 12 de abril, José Saramago se presentó en el Auditorio de Humanidades de la Universidad de California en Irvine para presentar su ponencia "The Illusion of Democracy", bajo el auspicio de la Escuela de Humanidades y del Departamento de Español y Portugués de UCI. Una noche antes, a iniciativa del "chair" Jacobo Sefamí y de la profesora Ana Paula Ferreira, el Departamento organizó una charla informal con el escritor en el Alumni House de UCI. Estudiantes, profesores y allegados tuvieron la oportunidad de dialogar por más de dos horas sobre distintos aspectos de su obra y de su carrera.

En las páginas que siguen incluimos el resultado de ese encuentro, donde el escritor ibérico habla de algunas anéctodas de su vida, de sus primeras novelas (entre ellas una inédita), de su compromiso con el socialismo, y de las adaptaciones de sus textos al cine (A Jangada de Pedra y Ensaio sobre a Cegueira). También expresó su opinión sobre la controversial teoría de "la muerte del autor" y sobre la situación política en Chiapas.

Saramago, que cumplirá 77 años en noviembre, es el único escritor de lengua portuguesa que ha recibido un Premio Nóbel de literatura. Algunas de sus novelas, como Lerantado do chao, han sido traducidas a más de quince idiomas. En la actualidad reside en las Islas Canarias.

NOTA: Debido a problemas con la grabación, no fue posible transcribir con exactitud las preguntas de los asistentes. En lugar de crear versiones aproximadas, decidimos presentar la charla con subtítulos intercalados, dándole por completo la voz a Saramago a lo 
largo de la charla.

\section{Leer para escribir}

Yo nací en el seno de una familia muy pobre y sin educación. Mi madre y mis abuelos fueron analfabetos toda su vida. Mi padre apenas sabía leer. En mi casa no teníamos libros. Mis primeros libros los compré cuando tenía 18 años, gracias a un amigo que me prestó el dinero. Estudié primaria y pasé a la secundaria (antes se le llamaba liceo) sin comprar libros y sin problemas. Tuve que hacer un curso técnico de mecánica antes de entrar a la universidad. Me preparé por cinco meses, y luego trabajé en un taller de mecánica por dos años. Al cabo de esos dos años, empecé a trabajar en otras cosas distintas (como dibujante, por ejemplo), y bueno, entonces siguió la vida.

Yo leía muchísimo, sobre todo en las bibliotecas públicas. Muchas veces no entendía lo que estaba leyendo. Una de mis primeras lecturas de ese tiempo, tendría 16 ó 17 años, fue el Paraíso perdido, de Milton, con ilustraciones espectaculares: los diablos, satanás, los ángeles rebeldes... Yo creo que, sin que me diera cuenta, hay mucho de ese texto en El evangelio segín Jesucristo.

Todas mis lecturas de esa edad tuvieron mucho efecto en mi primera novela, Terra do pecado, que publiqué en 1947. Ese año resolví los tres problemas: uno, que ya había hecho antes, era plantar un árbol; otro, publicar la novela; y por último, nació mi hija. Por lo tanto me quedé desobligado, cuando todavía era muy joven, de esa frase que no todos pueden cumplir.

En el fondo, Terra do pecado no es una buena novela, tanto que ni siquiera me puedo acordar del argumento. No he vuelto a leerla. Cuando se cumplieron 50 años en el 97, en una conspiración entre el editor y mi mujer, se reeditó. No la leí, no la revisé, ni me preocupé mucho. Terra do pecado no tiene nada que ver con la persona que soy hoy. Tengo un problema con esa novela: debería haberse llamado $\mathrm{La}$ viuda. Claro, ustedes podrían preguntarme qué sabía yo a esa edad de una viuda. Tampoco podía decir que supiera mucho de pecados. No sabía nada. La suerte fue que me encontré con un editor a quien le interesó la novela, así no ture que pagar. Me dijo: "Yo le voy a publicar esto, usted es muy joven y vamos a ver qué pasa. Pero antes vamos a cambiarle el título por otro más comercial. Voy a pensar en otro". Entonces le dije que yo ya tenía un título. A mí no me importó porque yo quería publicar. Y así la novela pasó a llamarse Terra do pecado.

Su reedición tuvo el éxito que no alcanzó antes. Sospecho que los 
lectores no se dan cuenta, o les da igual, o no entienden la diferencia que existe entre aquella novela y lo que estoy haciendo ahora. Parece que lo que cuenta para ellos es el nombre del autor. Inclusive he tenido que admitir varias veces, para algunos lectores, que ésa es mi mejor novela.

Aprendí allí [con esa novela] una lección: si uno no lee, no escribe. Puedes dar todas las vueltas que quieras, pero para escribir hay que leer. No todos los que han leído pueden llegar a ser escritores. Pero escritor que no haya leído todo lo que podía llegar a leer no creo que exista.

\section{Una novela inédita y un largo silencio}

Escribí otra novela que se quedó inédita y se quedará inédita. Algunos me han alentado a que la publique, pero no quiero vover a esas cosas que escribí de chico. Un amigo mío en el 49 ó 50 la llevó a una editorial para ofrecerla a la publicación. Fue una idea un poco ingenua, porque los milagros no se repiten, y el milagro de la primera novela no se repitió. La obra desapareció. Hace unos años - yo ya era relativamente conocido- en el 88 ó 89 , recibí una carta de la editorial que [decía que] habían encontrado la novela cuando estaban reorganizando los archivos, y se ofrecieron gustosamente a publicarla. Claro, les dije que no. Recogí la novela, me la llevé a casa, y mientras yo viva no se publicará. Pueden estar seguros de que no la destruiré. No puedo destruir lo que es parte de mi vida; el tiempo ya se encargará de eso. El tiempo lo destruye todo y cuando lo hace es para siempre.

Los 20 años siguientes después de la publicación de la primera novela me mantuve en silencio. Cuando digo en silencio no significa sólo en cuanto a publicar sino a escribir. En el año 66 publiqué un libro, y después unos cuantos más hasta el 75 . Hoy, si me pregunto por qué dejé de escribir, creo que puedo llegar a una conclusión: me di cuenta de que no tenía nada que valiera la pena decir; así que era mejor callar. "No tengo nada que decir; por lo tanto me callo". De joven no lo hubiese dicho, pero cuarenta años después lo puedo decir.

En el 75, viví la revolución de abril, como muchísimos otros, más en la calle que en el despacho. Era editor de un periódico, quizás el más importante de entonces, llamado Diario Noticias. En ese año, el contragolpe de la derecha irrumpió en el movimiento revolucionario, y de pronto me encontré en la calle porque me comprometí demasiado con la revolución. Me encontré sin trabajo y consciente de que las posibilidades de encontrar trabajo eran mínimas. Quizás me había 
quemado como periodista. Así que tomé la decisión más importante de mi vida de escritor: no buscar trabajo, vivir de una crónica, de algo así. Tenía 53 años. Yo no tenía nada que valiera la pena. No tenía importancia como autor. Todo lo que he escrito me ha llevado 20 años.

\section{La suerte de no tener trabajo}

Con la novela Manual de pintura y caligrafía, que se publicó en el 77 , comencé mi trabajo más auténtico. Esos años fueron un poco duros; me pregunto qué habría hecho si después de esa novela del 47 hubiera seguido escribiendo. Creo que estaría hoy aburridísimo, sin nada que decir. En vez de eso, he escrito unos cuantos libros quizás en la misma línea de aquél. Si uno tuviera la seguridad de llegar a los 80 ó 90 años, de empezar a escribir con esa madurez y seguridad... He tenido una suerte infinita. Inclusive, tuve la suerte de no seguir en un periódico. Si la revolución hubiese triunfado sería un periodista o algo parecido.

Cuando tenía 18 años, al conversar con los amigos siempre surgía una pregunta de interés: “QQué creen ustedes que serán cuando sean mayores?" Recuerdo que dije que quería ser escritor. ¿Por qué lo dije? No lo sé. También dije: "Lo que tenga que ser mío llegará". Lo cual es una posición bastante fatalista, ya que uno puede quedarse esperando con los brazos abiertos. Hay algo que tengo claro: nunca he tenido prisa por nada, no he tenido nunca ninguna ambición; me he limitado a hacer lo que tenía que hacer. Esta frase: "Lo que tenga que llegar a mis brazos llegará", se confirma a lo largo de mi vida.

Eduardo Lourenço, un gran ensayista, un sabio, dijo en broma una vez: "Tu vida es un milagro". No sé si lo es, pero sí han sucedido algunos milagros.

\section{Al compás de la prosa}

Los años 75 y 79 fueron decisivos para que lo vino después, pero $\sin$ la conciencia de estar buscando algo que necesitaba. Hoy se puede decir que tengo mi propia voz narrativa: esa forma característica de narrar que no es original ni única (la manera de expresar la oralidad es infinita), pero que al sistematizarse se encuentra algo ausente en otro autor.

En el año 75 decidí ir a una ciudad del sur —el mar físicohistórico-social e ideológico-y a partir de ahí escribí Levantado do chão (1980). Viví 10 semanas en esa región. Quería escribir una novela no sobre el pueblo donde nací, ni para recordar mi propia niñez, nada 
autobiográfico; quería poner en pie un mundo rural y campesino, que ha hecho de mí la persona que soy. Esa novela - había recogido material para ella en el 76- fue escrita en el 79. Mientras tanto publiqué Manual de Pintura e Caligrafía (1977). Empecé a escribir sobre lo que pintaba, y luego a reflexionar sobre lo que había escrito. Decidí encargar a la editorial 200 ejemplares en plena guerra con Angola, creyendo que allí se enseñaría a escribir y a caligrafiar. Fue una decepción terrible porque ni siquiera tenía dibujos, no tenía nada. Si miramos la novela desde esta perspectiva, nos damos cuenta de que anuncia unas cuantas obsesiones de todo lo que he escrito después. La crítica le ha dado muy poca atención a ese libro, y él, en cierta manera, define lo que vino después.

La gente en el pueblo me preguntaba: “¿Cuándo vas a escribir la novela?" Decía: "Estoy pensando". Así que me senté a escribir. Escribí las primeras 25 páginas obedeciendo toda la convención que lleva a que uno tenga que poner un guión:

\section{- Mañana voy a tu casa.}

Estaba pidiendo más soltura, más libertad, menos ataduras. Entonces nació un narrador que no le importaba decirle al autor: "Me equivoqué antes, vamos a ponerlo aquî". Esa especie de presencia constante del autor en la novela, escrita en primera persona, que sería el pintor. Esa idea de que hay una materia que pide ser narrada, que no quiere aceptar ni trabas ni disciplina, sino su propia lógica discursiva. En el fondo, ese flujo narrativo aspira a una especia de animidad. Al igual que una pintura $-\mathrm{y}$ no hablo de una pintura por casualidad-. En el espacio de una pintura se puede poner todo, y todo está al lado de todo. Pero en la literatura no: nada está al lado de nada; todo es sucesivo; todo es discurso.

Si yo ambicionara crear una especie de modo narrativo que fuera, al mismo tiempo, pintura, que quiere enseñarlo todo, sería una pintura que se mueve. En cada momento va enseñando lo que hay que enseñar. en lugar de seguir una lógica narrativa que sale de un punto y llega a otro.

Cuando yo digo que narrar en el fondo es hacer música, hay unos cuantos puntos en las novelas mías en que ocurre esto. Algunas veces me dan ganas de desafiar a un lector preparado, como sois vosotros. Se trata de que a veces, lo que yo estoy diciendo ya está dicho. No se necesita añadir ni una palabra más. La frase está completa, el pensamiento, todo en su sitio. A pesar de eso, lleva tres, cuatro, cinco, palabras que no añaden rigurosamente nada, pero que son necesarias porque el compás no puede quedarse en el aire. La palabra tiene que 
quedar en su sitio. $Y$ eso no tiene nada que ver con el ritmo. El ritmo es otra cosa. Es lo que nosotros llamamos en portugués "compás". La frase no tiene por qué ser brillante, pero necesita de una densidad interior que es determinada por una construcción frásica, una coda que es el compás. No estoy diciendo que eso sea así siempre, pero cuando lo es se nota; y cuando se nota, cuando me doy cuenta de que la palabra se queda en el aire - no desde el punto de vista lógico, sino desde el punto de vista musical- añado cinco, seis palabras más que no significan nada, pero que completan el sentido. Porque no se puede quedar así: necesita música.

¿Cuántos modos existen para decir una palabra? Hay miles. Tomemos por ejemplo una palabra sencilla como "No". ¿Cómo podemos escribirla? "No", "¿No?" "iNo!" "No..." Una cosa extrañísima, cuatro modos únicos de escribir la palabra. Pero no es sólo la palabra sino la música de la voz. Pausas breves, pausas altas, como en la música: es exactamente lo mismo.

\section{La existencia de Ricardo Reis}

El hecho de que yo haya escrito una novela sobre un heterónimo de Pessoa, que es O Ano da Morte de Ricardo Reis, no quiere decir que tenga influencias directas de Pessoa, porque ellas no se notan, a menos que sea en una cita u otra. Lo que ocurrió con O Ano da Morte de Ricardo Reis, que escribí en el 83 y se publicó en el 84 es que tiene una relación muy antigua con mi conocimiento de la obra de Pessoa. Tendría 18 años cuando me encontré con una revista firmada Ricardo Reis. Yo creí -no sabía [la verdad] porque era muy ignorante- que existía un hombre que se llamaba Ricardo Reis. Este engaño o ilusión duró varios meses. Entonces una alma caritativa me dijo que no era un poeta sino un heterónimo; en ese tiempo yo no mucho sabía lo que significaba. Con mucho trabajo lo entendí.

La obra de Ricardo Reis [tiene] todo ese conceptismo, esa especie de melancolía infinita, esa especie incapacidad de vivir y de no entender, ese acto de contemplación continua en que él se encuentra, inventando mujeres que no existen y que no son más que idealizaciones. Me encantó por la belleza formal y de contenido. Hay una frase que he dicho que no tiene nada que ver con Pessoa. "Sabio es aquel que está contento con el espectáculo del mundo". Lo que coincide exactamente con la postura filosófica de Ricardo Reis. La sabiduría es no intervenir, quedarse sentado, observando el espectáculo del mundo. Si yo lo pensara hoy, diría es un pensamiento único. Pero entonces no se trataba 
de eso. Escribí O Ano da Morte de Ricardo Reis para decir al señor Reis que la sabiduría no consiste en contentarse con mirar el espectáculo del mundo. Y además la ética que [hay] en todo esto es la que menos se podría confundir con alguna idea de una supuesta sabiduría antigua.

Pessoa murió en el 35. Ricardo Reis, que estaba en Brasil -ésta es mi ficción-, vuelve a Portugal y muere en el 36. ¿Qué pasó en el 36?: La guerra civil española, el Frente Popular en Francia, la invasión italiana a Etiopía, la ocupación de Alemania por la Alemania Nazi, la creación de las milicias fascistas en Portugal... Este fue el año del huevo de la serpiente, que se rompió tres años después con la explosión de la II Guerra Mundial. No caí en la trampa de convertir a Ricardo Reis en un activista político, porque eso va en contra de su naturaleza. Tiene un momento al final cuando se da cuenta de que quizás haya estado equivocado, pero no pasa a la acción. Lo que pasa con Fernando Pessoa es que es una especie de Monte Everest, y todo lo que está alrededor de un escritor así es mucho más pequeño, en una sombra tremenda, y tiene que sobrevivir a ella. Pessoa ha influido en todo el mundo, pero nadie quiere reconocerlo. Ni yo. Bueno, yo sí. Porque en el fondo está ahí.

Cada novela mía es una entrada y una salida. Entro en ella y salgo de ella. La próxima entrada será algo que no tiene nada que ver con la anterior. Si me convirtiera en un novelísta histórico, me preguntaría ¿qué ha pasado en Portugal para convertirlo en novela?

\section{El autor no ha muerto}

Entremos en una polémica que no terminará nunca: me atrevería a decir que el narrador no existe. No se quién lo habrá inventado. Es una noción literaria muy reciente y científica. ¿Se sabe exactamente cuándo empezó a decirse: "El narrador es esto o aquello". ¿Hay una fecha, o un lugar, un señor, o una señora que lo ha dicho? ¿O nació así de una manera espontánea?

En el siglo XVII no se hablaba del narrador, en el XVIII tampoco, y diría que en el XIX todavía no aparecía tal noción. De pronto, de un momento a otro, se habla del narrador, y no sólo del narrador sino de narradores. Cuando yo digo que el narrador no existe, no es para que me tomen en serio, sino para que tomen en cuenta que yo soy un escritor del siglo XVII, y no tengo nada que ver con eso del narrador. Y esto se relaciona directamente con la pregunta. ¿Quién es ese señor que firma?

A mí me gustaría que el lector estuviera preocupado por el "autor". ¿Dónde está el narrador en una obra de teatro? La obra es 
ficción pero no tiene narrador. Uno no se da cuenta que allí hay alguien.

Asistí a un congreso en Canadá sobre literatura comparada. Había 800 o quizás más humanistas de todas partes del mundo, y me invitaron a dar una conferencia, como tradicionalmente lo hacen. Los temas eran variados, pero en ninguno de los títulos aparecía la palabra autor: no existía. El narrador sí, y mucho; todo estaba allí excepto el autor. Entonces pregunté "¿Por qué lo hacen?" Ellos respondieron: "Es que el estudio del texto desde la perspectiva biográfica del autor no existe". "El autor ha muerto", dijo Roland Barthes. "El autor ya no tiene nada que ver". Entonces, ¿para qué sirve el autor? ¿Es una mujer, o un hombre, es calvo, trabaja de pie, escribe con el ordenador, con pluma, o con máquina de escribir? ¿Es un señor que lleva dentro de la cabeza unas cuantas cosas? ¿Ha escuchado historias, ha leído libros, ha vivido, ha tenido experiencias? La respuestas a todo eso es lo que el autor lleva dentro de su cabeza y de ninguna más. [Otro autor] puede llevar unas cuantas cosas similares, pero no lo mismo. El autor es único e irrepetible. Se puede decir lo mismo en [un objeto] físico como el libro, pero lo que pasa en esa cabeza es único. El autor es un personaje más de su historia; tiene unas cuantas cosas que lo individualizan. Y se sienta a trabajar con lo que tiene. Luego viene el crítico y dice: "Esto viene de aquí, Esto viene de allá, y hay un narrador". Y no es que esto no se pueda o se deba hacer. De todo el conocimiento que poseen los críticos, el autor puede ser completamente ignorante. $Y$ es mejor que lo sea.

Cuando era joven practicaba tenis. Durante el partido, si me ponía a jugar pensando cómo tenía que mover la raqueta -que la pelota viene así, que debo pegarle así- seguramente la pelota iba a la red o afuera de la cancha. Todo tiene que estar en la cabeza organizado, preorganizado. Nadie se sienta a escribir una novela sin antes meditarlo. El escritor debe estar dispuesto $u$ organizado para entregarse a la escritura. Y creo que esto es una regla universal.

No creo en eso que dicen por ahí: "Con la vida del autor no se puede explicar una novela". Sin la vida del autor tampoco la podéis explicar. No es que sea indispensable, pero lo que pasa es que se está explicando otra cosa. ¿Por qué ese señor escribió esta obra, y qué ha pasado con él? ¿Quién era él para que esta obra exista y no otra? No sé si se ha vuelto al autor o no recientemente. Escuché que había una tendencia a querer volver al autor. $Y$ lo entiendo porque cada vez que se decida matar al autor, no queda más remedio que resucitarlo. Entonces, manténganlo vivo, quizás sin darle mucha importancia, pero la suficiente para no olvidarlo. 


\section{Orígenes de A Jangada de Pedra}

En primer lugar, soy portugués, después soy ibérico y en tercer lugar soy europeo (y eso si me da la gana). Europa no existe. $Y$ supongo que no existirá nunca. ¿Qué es lo que hace a Europa? ¿El centro europeo; el centro del centro, París; un centro periférico, Londres, Roma? ¿Y España y Portugal ya no lo son?

Europa no nos ha prestado nunca ninguna atención. Hemos sido despreciados, humillados. En el siglo XIX hubo un gobierno portugués que no llegó a entrar en función porque el admirante de la escuadra británica que regía en el momento no lo permitió. Las historias de las humillaciones nacionales —no sólo de Portugal, sino de los pequeños pueblos, de los pequeños países - es una historia interminable. Una humillación que no ha terminado, que seguirá y no terminará nunca. Incluso se dice que Africa empieza en los Pirineos. Entonces yo digo: "Vámonos en una balsa de piedra al sur".

Es verdad que hay una mala concepción del sur, una especie de mala conciencia de los que vivimos en el norte. Parece que de tanto remordimiento, de tanta catástrofe, de tanto genocidio, de tanto robo, tenemos que hacer algo. No podemos corregir la historia, pero quizás el día de mañana sea posible. En mi novela [A Jangada de Pedra] se habla del sur como otra posibilidad, no como el Dorado, sino como otra posibilidad. La Peninsula lbérica es transformada [en mi novela] en una isla, una balza que navega en dirección al sur y va a parar entre Africa y América. Es una utopía más. Es, en una palabra más sencilla, un disparate.

\section{Saramago va al cine}

Yo siempre había rechazado la adaptación de mis novelas al cine, porque no quería ver el rostro de mis personajes en la pantalla. Pero una profesora, Ivette Viró, me escribió una carta hace unos años para hacer una adaptación de la novela [A Jangada de Pedra]. Y finalmente va a transformarse en un film que empieza a rodarse el 16 de mayo. Hay otra novela que también está siendo adaptada en Canadá: el Ensaio sobre a Cegucira. Mi agente literario recibió casi 20 consultas de productores norteamericanos. ¡Dios mío! ¿Qué les daría por adaptar esa novela? Yo no quiero ni saberlo. A todas he dicho que no. Unos jóvenes de Canadá se mostraron tan ingenuos y sencillos, que les di el sí. 


\section{La diguidad zapatista}

Mis contactos con los zapatistas no son muy antiguos. He estado tres veces en el Estado de Chiapas. Se cuenta que los zapatistas eran tres o cuatro al principio. En un comienzo entraron a Chiapas con la intención de restituir los derechos indígenas: su dignidad, el reconocimiento de su estilo de vida, su idioma, su cultura. En fin, su particular forma de vivir, que no es la nuestra. No tenemos ningún derecho a imponer lo que a nosostros nos parece bien. ¿Por qué lo que a nosotros nos parece bien tiene que aplicarse a todo el mundo? Eso se llama ignorancia, o una forma disfrazada de la ignorancia. Pero lo es.

Lo que ha ocurrido con Marcos es que no lo han entendido. Lo que él ha dicho es que hay otra forma de vivir. Como escribió un día Eduardo Galeano: "Marcos decidió entrar en la niebla". Marcos se transformó en un indio como los otros. Es un trabajo lentísimo para hacer valer la presencia indígena.

Los zapatistas son probablemente dos mil o tres mil, quizás menos. No podemos preguntar: ¿cómo es que han sobrevivido allí, rodeados por sesenta mil soldados? Una tercera parte del ejército mexicano ocupa el estado de Chiapas. El ejército mexicano atacó al ejército zapatista, pero la inteligencia de ese que se hace llamar el Comandante Marcos fue mucho más allá de lo que esperaba el gobierno mexicano: tiene una capacidad política y estratégica para administrar las intervenciones y los silencios.

A veces pasamos meses sin saber de Marcos. $Y$ nos preguntamos: "¿Por qué no hablará?" Entonces aparece en el momento justo. Para dar un ejemplo, cuando Fox asumió la presidencia, Marcos publicó un comunicado diciendo: "Vamos a ir Ciudad de México". Al día siguiente, como lo tenía planeado, salió para la capital.

Yo he dicho y sigo diciendo que hasta que no se resuelva el problema de Chiapas, díficilmente otro problema se podrá resolver. Chiapas es una piedra en el medio del camino; si no se remueve, no se podrá seguir. A Fox le han hecho saber eso. Fox, en su camino a la presidencia, dijo: "el problema de Chiapas lo resuelvo en 15 minutos". Vamos a ver cuántos minutos más va a necesitar ahora. La opinión pública mundial está con los zapatistas. Pero los medios de comunicación lo que han hecho es ridiculizarlos, despreciarlos. Marcos dijo un día a los indígenas: "Yo los llevaré a México". Y cumplió. ¿Quién iba a pensar o imaginar que un comandante zapatista hablaría en México y marcharía hacia la ciudad con los pasamontañas? Pues ocurrió. Ahora comienza el gran debate para aprobar esa ley [sobre los 
derechos indígenas]. Hay una reivindicación que difícilmente el gobierno y el Congreso mexicano pueda aceptar: el poder de los indígenas sobre tierras que se consideran mexicanas.

Chiapas aporta $70 \%$ del agua que se consume en la capital. Y en Chiapas, los indígenas no tienen agua. Lo que está en el subsuelo de Chiapas en petróleo, uranio: lo que las multinacionales están esperando. Es igual a lo que sucede en Africa: están esperando que se acaben los negros. Cuando se mueran los negros de SIDA, de enfermedades, de hambre, de guerras civiles, el continente quedará despejado; entonces a disfrutar. ¿Por qué los indígenas de México y de Chiapas no pueden decir: "Esto es nuestro y queremos vivir de acuerdo a nuestras tradiciones", las cuales no tienen por qué ser las costumbres occidentales? ¿Por qué tienen que imponerse las culturas? En los tiempos de la conquista siempre iban dos entidades, el soldado y el fraile. El soldado para decir: "Si no haces lo que quiero te corto la cabeza", y la cortaba. Y el fraile para decir: "Estas creencias son falsas; yo traigo conmigo el verdadero Dios". Ahí está el absurdo: alguien que diga que lleva consigo el verdadero Dios. Si existe Dios hay sólo uno, $y$ todos tienen derecho de verlo donde quieran. A verlo en el pájaro que está cantando en este momento, en la montaña, o en un hombre colgado de una cruz. Pero que todo eso sirva para que nos enfrentemos unos a otros es absurdo, porque las religiones no han servido nunca para acercar a los seres humanos. Nunca.

Los indígenas quieren vivir su cultura. Paradójicamente, si ha habido un tiempo en que se habló del respecto a la diferencia, es el nuestro. Todo el mundo está diciendo que hay que respetar las diferencias. $Y$ hay algunas diferencias que se han llegado a respetar; pero hay otras, en el caso de los indígenas, que no se han respetado. ¿Por qué ese empeño de querer imponer la cultura occidental? El mundo ha vivido todo lo que ha vivido para llegar a la perfección de lo que supuestamente somos hoy.

--Oscar González University of California, Irvine 